\title{
Evaluation of adherence to measures for the prevention of surgical site infections by the surgical team
}

\author{
Avaliação da adesão às medidas para a prevenção de infecções \\ do sítio cirúrgico pela equipe cirúrgica \\ Evaluación de la adhesión a las medidas para la prevención de \\ infecciones del sitio quirúrgico por el equipo quirúrgico
}

\section{Adriana Cristina de Oliveira ${ }^{1}$, Camila Sarmento Gama ${ }^{1}$}

${ }^{1}$ Universidade Federal de Minas Gerais, Nursing School, Belo Horizonte, MG, Brazil.

\section{ABSTRACT}

Objective: Evaluate pre- and intraoperative practices adopted by medical and nursing teams for the prevention of surgical infections. Method: A prospective study carried out in the period of April to May 2013, in a surgical center of a university hospital in Belo Horizonte, Minas Gerais. Results: 18 surgeries were followed and 214 surgical gloves were analyzed, of which $23(10.7 \%)$ had postoperative glove perforation detected, with $52.2 \%$ being perceived by users. Hair removal was performed on $27.7 \%$ of patients in the operating room, with the use of blades in $80 \%$ of the cases. Antibiotic prophylaxis was administered to $81.8 \%$ of patients up to 60 minutes prior to surgical incision. An average of nine professionals were present during surgery and the surgery room door remained open in $94.4 \%$ of the procedures. Conclusion: Partial adhesion to the recommended measures was identified, reaffirming a need for greater attention to these critical steps/ actions in order to prevent surgical site infection.

\section{DESCRIPTORS}

Surgical Wound Infection; Operating Rooms; General Surgery; Gloves, Surgical; Infection Control; Perioperative Nursing. 


\section{INTRODUCTION}

Surgical site infections (SSI) are common complications affecting patients who undergo surgery, corresponding to $38 \%$ of infections in this population ${ }^{(1)}$.

In Brazil, they have occupied third place among all Healthcare Associated Infections (HAI), and are found in approximately $14 \%$ to $16 \%$ of hospitalized patients ${ }^{(2)}$. Overall in the United States, SSI have represented the second largest group of HAI that affect most patients, reaching 500,000 cases, causing an average of 3.7 million extra days of hospitalization, more than 1.6 billion dollars of extra costs for hospital bills, as well as physical, emotional and financial losses for the affected patients ${ }^{(3-5)}$.

SSI occurrence depends on factors related to the patient and the surgical team, but ultimately to the possibility of surgical wound contamination during the procedure; considering that the earlier microbial contamination occurs during a surgery, the greater the chance of patients developing SSI due to the introduction of microorganisms into the surgical opening being manipulated ${ }^{(6)}$.

Thus, multiple risk factors may contribute to the onset of SSI, considering the pathogen, the patient and the surgical procedure. Aspects associated with the pathogen include microbial load involved, their pathogenicity and infectivity. Those related to the patient can be expressed by the extremes of age, pre-existing conditions, length of hospitalization, and nutritional status, among others. As for surgical procedures, in the intraoperative phase, can be described the hair removal, surgery area preparation, antisepsis of surgeon's hands, antimicrobial prophylaxis, surgical technique, problems with patient's oxygenation and normothermia, among others ${ }^{(1,3,7)}$.

Although SSI is known to be multifactorial, the surgical team plays a key role in the prevention of factors related to the surgical procedure during the pre- and intraoperative period, whether in regard to the number of people in the operating room, in transit, or excessive conversing by the professionals within the operating room at the time of surgery, to the door movement, the ventilation system, timely decisions and type of antimicrobial prophylaxis, scrub prepping and adequately preparing the patient's skin (operative area) and hands of the surgical team (degermation) ${ }^{(7)}$.

Proper implementation of these measures during preand intraoperative care can directly interfere in the pathogenesis of SSI since they contribute to the reduction/elimination of microorganism transference to surgical incision, which is the sine qua non (without which it could not be) factor for the development of infection ${ }^{(7-8)}$.

Although the importance of these measures is well described in the literature and in national and international manuals, few studies address its actual implementation in the routines of operating rooms ${ }^{(8)}$. Thus, the present study aims to evaluate the adherence to measures for preventing surgical site infections by surgical teams of operating rooms in a public university hospital of Belo Horizonte, Minas Gerais.

\section{METHOD}

A prospective observational study conducted in a surgical center of a large public teaching hospital in Belo Horizonte between April and May 2013.

Data collection was performed in the mornings and afternoons by a researcher for one month, according to the scheduling routine of the three most popular surgical specialties in the sector in the period from 2010 to the first half of 2012, which were: digestive system/gastrointestinal surgery (GI) 4,315 surgeries/year; pediatric surgery (PEDSUR) 2,636 surgeries/year; and cardiovascular surgery (CVS) 2,370 surgeries/year.

Surgical procedures included in this study were in accordance to the National Healthcare Safety Network (NHSN) operative procedure of 2013, which are those performed in patients whose admission dates and medical discharge are distinct (internal) or are not distinct (external); performed in the operating room with at least one incision of the skin or mucosa, including laparoscopic approaches; followed by primary incision closure before patients leave operating room, which is the approximation of all tissues regardless of the presence of threads, drains or other devices through the incision; and which are described in this manual ${ }^{(9)}$. Collection was divided into two phases, as described below.

In phase I the researcher approached each member of the surgical team prior to surgery to obtain their consent for having their gloves used during surgery being submitted to integrity analysis by completing a perforation verification test, based on the European Standard EN 455-1 ${ }^{(10)}$, which consists of filling each collected glove with $1 \mathrm{~L}$ of water, then observing and manually compressing each finger space to assess the presence of holes.

At this time, the teams were informed about the objectives and the relevance of the research. A clear and Informed Consent (IC) form was presented in order to obtain the formal consent of the participants to provide their sociodemographic information and other data, such as: dominant hand used for surgery, performed function on the surgical team and type of glove used.

In phase II, the same researcher without the individuals present in the operating room having previous knowledge, claiming the need to accompany the surgical procedure to collect surgical gloves at the end and/or during the procedure, collected the following data through medical record review: preoperative bathing, American Society of Anesthesiologists - ASA classification and potential of surgery contamination.

While still in this stage, hair removal and antimicrobial prophylaxis (choice of agent, time of administration before incision, the need of administering another dose during surgery and its administration) were directly observed and/or checked in the anesthesia team's notes. Antibiotic prophylaxis was categorized as adequate, satisfactory or unsatisfactory. Adequate for those that selected and administered the first choice of drug in accordance with local protocol, when there was an indication of use or absence of antimicrobial prophylaxis and when there was no indication. Satisfactory for those which used a replacement drug instead of the first 
choice of drug in accordance with local protocol, able to cover the micro-organisms of the surgical area involved. And unsatisfactory when selected drugs and administered were incompatible with the local protocol recommendations, or the absence of antimicrobial prophylaxis when there was an indication.

The use of accessories and surgical scrubs was also observed at the same time.

Surgical gloves were collected in individual plastic bags marked with the initials of each participant, type of glove and the hand used (right, left), way it was used (inner glove/ external or single) and usage time. Participants' data were recorded in a questionnaire that contained their information collected in Phase I, including dominant hand. At the end of the surgery, all gloves were taken to a support room adjacent to the operating room, intended for receiving surgical instruments used in surgery and for primary care before being forwarded to the Sterilized Material Center for processing. These rooms had sinks and countertops. The researcher remained attired in personal protective equipment: examination gloves, coat, goggles, mask, cap, closed shoes and shoe covers to preserve their safety.

At a third time after phases I and II, participants were again individually addressed and clarified about phase II being carried out. As shown in international studies, keeping the team unaware of observations is intended in order to avoid the "Hawthorne Effect"(11). At that time, professionals were guaranteed the possibility of disagreeing with the observations made about their performance, with the possibility of not consenting to the use of these observations, and thereby guaranteeing their removal from the analysis.

Surgeons, preceptors, residents and scrub nurses were eligible for Phase I of the study when present in the team, regardless of gender and of age. For phase II, all individuals present in the operating room were eligible from the moment that the incision was made until the closing of the wound, also regardless of gender and of age.

Data were collected, entered and anonymously analyzed with the aid of statistical software Statistical Package for Social Sciences (SPSS) - Version 13.0. A descriptive statistical analysis was performed.

The project was approved by the Ethics Committee of the Federal University of Minas Gerais, protocol number ETIC 114116512.1.0000.5149.

\section{RESULTS}

\section{DEMOGRAPHICS AND CHARACTERIZATION OF SURGERIES}

49 individuals of surgical teams were approached; 32 of the digestive system, seven cardiovascular and 10 pediatric. Of this total, $31(63.3 \%)$ were male, 38 (77.6\%) were trained in medicine, seven (14.3\%) were medical students and four (8.2\%) were nursing technicians. The average age was $33.1 \pm 10.9$ years (23-77 years). For their roles in the sector, 15 (30.0\%) were preceptors, 23 (46.9\%) were residents, seven (14.3\%) medical students and four (8.2\%) nursing technicians.

Out of the eighteen evaluated surgeries, 12 (66.6\%) were clean, three $(16.7 \%)$ were potentially contaminated and three $(16.7 \%)$ were contaminated. The ASA patient classification varied from I, II and III, with six patients representing each category.

Twelve GI surgeries, three PEDSUR and three CVS were followed. There was a higher number of GI surgeries compared to the others due to the greater quantity of scheduled surgeries that met the criteria of this study. The average duration of the surgeries was 135.2 minutes \pm 54.3 minutes (ranging from 30 minutes - 239 minutes).

\section{Preoperative PROCEDURES}

Hair removal was performed on five $(27.7 \%)$ patients inside the operating room, four $(80.0 \%)$ with a blade and one $(20.0 \%)$ with a clipper. Hair was removed in under 60 minutes for all of them. None of the patients went to the operating room with the incision area hairless. The procedures that required hair removal were: videolaparoscopy cholecystectomy, unilateral inguinal hernia, arteriovenous fistula confection, mitral valve replacement and intestinal/ bowel transit reconstruction, with hair having been removed from the chest, pubic area and armpits.

As for preoperative bathing on the day of surgery, 15 (83.3\%) patients had a shower. $11(73.3 \%)$ had it in the hospital and four (26.7\%) at home. It is noteworthy that antiseptic soap (chlorhexidine) was used in only one $(6.7 \%)$ of the preoperative baths, in the morning of the mitral valve replacement surgery (CVS).

Antibiotic prophylaxis was used in 14 (77.8\%) patients (Table 1), antibiotics were already being administered in two (11.1\%) patients due to a previous infectious condition, in one case $(5.6 \%)$ the patient had a recommendation for prophylaxis but did not receive it, in another case (1;5.6\%) the patient had no indication, but received the drug nonetheless. The antibiotic of choice was cefazolin in 13 (92.9\%) cases, and in one (7.1\%) case metronidazole was associated with ceftriaxone.

Table 1 - Distribution of antimicrobial use as recommended by the local protocol, ASHP manual and discussion with internal expert * - Belo Horizonte, MG, Brazil, 2013.

\begin{tabular}{lc}
\hline \multicolumn{2}{c}{ Use of antimicrobial } \\
\hline Antimicrobial appropriateness & Yes \\
\hline Suitable & $11(78.6 \%)$ \\
Inappropriate & $0(0 \%)$ \\
Satisfactory & $3(21.4 \%)$ \\
\hline Total & $\mathbf{1 4}(\mathbf{1 0 0 . 0} \%)$ \\
\hline${ }^{*}$ Cases not described in protocol or in controversy with AHSP manual and protocol
\end{tabular}
were discussed with a medical specialist in hospital infection control of the institution.

Antimicrobial was administered intravenously to all patients by the surgical team at least 60 minutes before the incision in $78.6 \%$ (11) cases, more than 60 minutes before incision in $7.1 \%$ (1), and more than 30 minutes after the incision in $14.3 \%$ (2).

Of the 14 patients receiving antimicrobial six (42.9\%) received another dose during surgery. The drug of choice and administration method was the same as the first, but 
with reduced dosage. Also, the time of administration was about 180 minutes after the first in five (83.3\%) of the cases.

\section{INTRAOPERATIVE PROCEDURES}

With respect to the time when the operation room door remained closed, it can be emphasized that it was accomplished in only one (5.6\%) surgery. The doors remained open during the entire surgical procedure in 16 (88 9\%) cases, and it remained open in one $(5.6 \%)$ during $90 \%$ of the surgery time. Time was tracked after the beginning of the surgical incision until its closure. Moments when a door was opened for people or equipment to go though were not considered in the count.

In order to evaluate the recommendation of limiting the number of individuals who enter and remain in the operating room to the necessary quantitative, as recommended by the Centers for Disease Control and Prevention (CDC) $1999^{(1)}$ guidelines for the prevention of SSI, it was identified that nine professionals in the operating room would be the ideal number of professionals in more complex surgeries and five for less complex, considering the role played by each member. Thus, in more complex procedures it was observed that there was a need for a surgeon on the team (preceptor), three medical assistants (residents of surgery), a scrub nurse, a circulating nurse, a preceptor anesthesiologist, a resident anesthesiologist, and an X-ray technician. For minor procedures, a surgeon (preceptor), an assistant doctor (surgery resident), a circulating nurse, a preceptor anesthesiologist, and a resident anesthesiologist.

However, the average number of people found was nine professionals (range 5-15), regardless of the size of the surgery, with the researcher not being counted. In this sense, only three (16.7\%) surgeries had the optimum number of people according to the functions to be performed during the procedure.

Finally, we evaluated the use of surgical attire and accessories by members of the surgical team who were in contact with the surgical field (surgeon, medical assistant and scrub nurse). In this assessment, the total number of participants $(\mathrm{N}=49)$ evaluated became 70 as the same individual participated in more than one procedure because their attire and accessories were analyzed after each accompanied surgery, and not one time. The use of protective gear from this total was as follows: 10 (14.3\%) used goggles, 41 (58.6\%) used shoe covers and others used rubber shoes or ordinary shoes like sneakers without shoe covers, five (7.2\%) used the cap properly covering their hair and ears, 70 (100.0\%) used a gown, $68(97.1 \%)$ used the mask properly positioned and $70(100.0 \%)$ used surgical gloves.

When it comes to accessories, none of the surgical team members fully attired in gloves and gowns were wearing a ring, bracelet or watch, and those who wore a necklace/ chain $(11 / 15.7 \%)$ or i.d. badge (18/25.7\%) maintained these accessories inside the gown at all times, only exposing the earrings (19 / 27.1\%) and eye glasses (21/30\%).

\section{Glove perforation and usage time}

Glove perforation occurred in 12 (66.7\%) of the accompanied surgeries. The gloves used were natural latex from a single commercial brand. 214 gloves were analyzed, of which $23(10.7 \%)$ had perforation detected in the testing. The perforated gloves were used by 16 (32.7\%) participants, of which nine (56.3\%) were residents. 12 (52.2\%) of the total detected perforations were noticed by the users.

The same participant was approached more than once for the collection of gloves in separate procedures, so that the total of 49 individuals became 75 . Thus, the distribution of the gloving type in relation to the duration of surgery is shown in Table 2.

Table 2 - Distribution of glove type in relation to the duration of the surgery - Belo Horizonte, MG, Brazil, 2013.

\begin{tabular}{ccccc}
\hline \multicolumn{5}{c}{ Gloving type } \\
\hline $\begin{array}{c}\text { Surgery } \\
\text { duration }\end{array}$ & $\begin{array}{c}\text { Single } \\
\text { gloving }\end{array}$ & $\begin{array}{c}\text { Double } \\
\text { gloving }\end{array}$ & $\begin{array}{c}\text { Single } \\
\text { followed } \\
\text { by double } \\
\text { gloving }\end{array}$ & Total \\
\hline $\begin{array}{c}\leq 149 \\
\text { minutes } \\
\geq 150\end{array}$ & $32(42.7 \%)$ & $4(5.3 \%)$ & $0(0 \%)$ & $36(48.0 \%)$ \\
minutes & $28(37.3 \%)$ & $10(13.3 \%)$ & $1(1.4 \%)$ & $39(52.0 \%)$ \\
\hline Total & $\mathbf{6 0 ( 8 0 . 0 \% )}$ & $\mathbf{1 4}(\mathbf{1 8 . 6} \%)$ & $\mathbf{1 ( 1 . 4 \% )}$ & $\mathbf{7 5 ( 1 0 0 . 0 \% )}$ \\
\hline
\end{tabular}

Double gloving was adopted for the following procedures: videolaparoscopy cholecystectomy $(1 ; 7.1 \%)$, unilateral inguinal hernia $(2 ; 14.3 \%)$, incisional hernia repair $(2$; $14.3 \%)$, exploratory laparotomy $(4 ; 28.6 \%)$, hemorrhoidectomy $(1 ; 7.1 \%)$, gastroplasty $(2 ; 14.3 \%)$ and bowel transit reconstruction $(2 ; 14.3 \%)$.

The function performed by the users of the perforated gloves in the surgery was: surgeon $(8 ; 50 \%)$, followed by the assistant doctor $(4 ; 25 \%)$ and scrub nurse $(4 ; 25 \%) .15$ (93.8\%) of the participants were right-hand dominant. The characteristics of the perforations are in Table 3.

Table 3 - Perforation of surgical gloves in relation to usage time, dominant hand and quantity of perforation - Belo Horizonte, MG, Brazil, 2013.

\begin{tabular}{lcc}
\hline VARIABLE & N (23) & $\%$ \\
\hline Perforated glove usage time & 7 & 30.4 \\
$\leq 29$ minutes & 6 & 26.1 \\
30 to 119 minutes & 10 & 43.5 \\
$\geq 120$ minutes & & \\
Hand on which the perforation occurred & 8 & 34.7 \\
Single gloving on right hand & 10 & 43.7 \\
Single gloving on left hand & 4 & 17.3 \\
Outer glove on left hand & 1 & 4.3 \\
Outer glove on right hand & & \\
Quantity of glove perforation & & \\
One perforation & 20 & 87.0 \\
Two glove perforations & 3 & 13.0 \\
\hline
\end{tabular}


Of the total perforated gloves (23), nine (39.1\%) occurred on the dominant hand of the user and $14(60.9 \%)$ on the nondominant hand. The regions most perforated were index finger (46.2\%), then the thumbs (23.1\%) and palm (15.4\%).

\section{DISCUSSION}

This study had some limitations, such as no post-operative follow-up of the patient to evaluate the association between perforated gloves and non-compliance with infection prevention measures and the SSI outcome. As these patients were not followed, it was also not possible to assess the continuity or otherwise of the prophylaxis antibiotic. Another limitation was the time tracking of surgical procedures (one month). Cancellations and the availability of human resources contributed to the quantitative data.

Some proposed measures for the preoperative prevention of SSI were not fully adhered to by the observed professionals. With regard to the removal of hair, the recommendation in accordance with national and international guidelines is that the hair is not removed unless it interferes with the surgery. In cases of removal, it is recommended to use electric clippers immediately before surgery ${ }^{(1,6,12-14)}$.

Preoperative bathing is aimed at removing dirt and part of the microbiota on the patient's epidermis/skin. In regard to this practice, some patients took a shower in the morning of the surgery without using an antiseptic soap. This subject is controversial among manuals and guidelines that address the issue because although some antiseptic agents are able to significantly reduce microorganisms on intact skin and have a wide spectrum of activity, and fast, persistent and cumulative action, there is not sufficient scientific evidence to demonstrate the reduction of the SSI rate after a preoperative bath ${ }^{(6-8,12-14)}$.

Bathing with an antiseptic at least one night before surgery has been referenced in various global guidelines, recommended since the CDC guideline of 1999, which is for many their current important guideline reference ${ }^{(6,12,15)}$.

The surgical antibiotic prophylaxis is one of the most important methods available for preventing $\mathrm{SSI}^{(3,7)}$. It aims at reducing the concentration of potential pathogens in the incision area, contributing to significant reductions in infection rates ${ }^{(3,14-15)}$.

Regarding the use of registered antimicrobial prophylaxis, most (78.6\%) were appropriately prescribed as the protocol of the institution, and some (21.4\%) were suitable to replace the drug of choice in accordance with local protocol, being however also considered able to cover the microorganisms of the surgical area involved, thereby being a satisfactory choice in their spectrum of action. The antibiotic of choice in $90.9 \%$ of cases was isolated cefazolin, a second-generation cephalosporin. Cephalosporins provide good penetration in surgical wound, are safe and effective against many Gram-positive and Gram-negative microorganisms, and are reasonably-priced ${ }^{(1,5,7)}$.

Intravenous administration was used for all patients, conforming to the recommendations of manuals $s^{(1,15)}$ to be the quickest route to initiate the action of drugs. The timing of antibiotic administration should be calculated in order to ensure the bactericidal serum and tissue concentration at the time of surgical incision ${ }^{(1,13,15)}$.
For most agents, antimicrobial prophylaxis should be infused between 30 and 60 minutes prior to surgery, preferably at the time of anesthesia induction ${ }^{(7,12-13)}$. This recommendation was met by most surgical teams (81.8\%).

It is important to consider the antimicrobial repetitions in intraoperative surgery where the duration exceeds the half-life of the drug in order to maintain adequate bactericidal serum and tissue level. For antimicrobial half-life $<1$ hour, new administration is suggested every 2 hours, and antimicrobials with half-life $>1$ hour every 3-4 hours ${ }^{(1,8,12)}$. As the half-life of cefazolin is $>1$ hour (in patients with normal renal function it is 1.2 to 2.5 hours), it was observed that $66.7 \%$ of the repetitions were performed correctly within three hours after the first dose.

As for attire, the recommendation for the surgical team wearing gowns, sterile surgical gloves, masks and caps covering their hair during surgery is well-established ${ }^{(1,6,14-16)}$. Although microorganisms coming from the skin, mucosa and hair of the surgical team is a proven fact, there is no evidence demonstrating the relationship between the use of attire and reducing the incidence of $\mathrm{SSI}^{(1,14-15)}$.

However, the use of these protective barriers seem to minimize patient exposure to microorganisms from the surgical team and vice versa ${ }^{(1,15)}$. From this perspective, it was observed the need to improve adherence to the correct use of attire, being only the gown/coat and surgical gloves used properly $100 \%$.

The use of protective gear by the surgical team on the hands and arms is not encouraged by the guidelines as it contributes to omit the dirt and hinders the contact of antiseptic agent with a contaminated area, as well as facilitating the perforation of used gloves. However, there is insufficient scientific evidence on the use of these items and the risk of SSI ${ }^{(1,6,14,16)}$. In this sense, adherence to this recommendation by the professionals was satisfactory, since none of them used rings, bracelets or watches.

With regard to maintaining the door closed during the entire surgical procedure except for the passage of equipment/materials and professionals ${ }^{(1)}$, it was noted that this step had low adhesion, being accomplished in only one $(5.6 \%)$ of 18 surgeries monitored. In a similar study in Italy ${ }^{(8)}$, this rate was $36.9 \%$, demonstrating the need to strengthen the importance of using this recommendation in surgical routines.

Finally, it became clear that the number of participants was higher than that required for surgery. Although it is advisable to limit the number of people to what is necessary in operating rooms due to the activity being performed during the procedure ${ }^{(1-14)}$, the result can be partially explained by the fact that the study institution is a teaching hospital, where students watch the surgeries for learning. However, limiting these students per procedure is suggested, distributing them evenly between different surgeries in an attempt to meet the recommended measure.

The use of sterile surgical gloves is also a key measure for the prevention of SSI to provide a physical barrier for potential microorganisms present in the hands of health professionals, the environment and patients ${ }^{(6)}$. Failure in the 
integrity of the glove enables the transfer of micro-organisms ${ }^{(17)}$, capable of doubling the risk of $\mathrm{SSI}^{(15)}$.

The incidence of perforation of the gloves in this study was $10.7 \%$. This value is consistent with other studies, estimated on the average occurrence of $18 \%$ (ranging 5-82\%) of (micro) perforations/tears in gloves while performing procedures. Such perforations usually occur on the non-dominant hand and in most cases, the index finger, followed by the thumb, on the professionals working as a surgeon, which was confirmed in this study ${ }^{(17-22)}$. The fact that the surgeon handles sharp instruments more often than the other team members using their dominant hand is a possible cause of the occurrence of accidents on the opposite hand ${ }^{(19,22)}$.

The higher incidence of perforations between residents can be justified by the lower level of skill and dexterity due to their little professional experience ${ }^{(22)}$.

Longer surgical procedures have been associated with increased rates of glove perforations ${ }^{(19,22)}$. One explanation would be the increase of surgical team fatigue over time that can lead to inattention ${ }^{(22)}$. The frequent exchange of surgical gloves in longer procedures have been related to the reduction of microbial contamination rate ${ }^{(23-24)}$, the replacement thereof being suggested during prolonged surgeries, preferably every 90 minutes $^{(25)}$.

The protocol of the study institution recommends that in a surgery with prosthesis implantation or duration above 3 hours the gloves should be replaced in the second hour or at different stages of the procedure, such as incision and preparation of the site of the prosthesis/implant, prosthesis placement and closure.

In addition to more frequent glove changing, using double gloving is recommended to maintain the physical integrity of gloves; this consists of the use of two gloves with the outer glove serving as a protective barrier of the inner glove $\mathrm{e}^{(1,6-7,12)}$. Its use is recommended in high-risk glove perforation situations, for example, orthopedic surgery with excessive use of sharp scalpels and involvement with bone fragments, and that the consequences of contamination are catastrophic in prosthetic implants ${ }^{(6)}$.

In this study, a small number of users realized they had perforated their gloves. The lack of awareness prevents users from changing their gloves, causing many to use them until the end of surgery, thus exposing the patient to microorganisms of their microbiota and vice versa. Thus, in order to help increase this perception by the user, it is recommended to use colored indicator gloves ${ }^{(26)}$.

In the hospital environment, more than half of adverse events (AEs) arise from surgical care and approximately 50\% of these are considered preventable ${ }^{(27)}$. Among the most common AEs in surgical patients are wound infection ${ }^{(27)}$, considered preventable depending on the care provided in the preoperative, intraoperative and postoperative periods.

In this sense, all the professionals involved in these steps are responsible for the quality of care and patient safety, including nurses and nursing technicians who work in the prevention and control of infection and other $\mathrm{AEs}^{(28)}$.

\section{CONCLUSION}

This research has identified partial adherence to some measures recommended preoperatively and intraoperatively by global benchmarks to prevent SSI.

Failures occurred in hair removal of the patient with the use of blades, which is not recommended anymore; keeping the door open during the surgical procedure; and the number of individuals in the operating room, which was higher than necessary for the development of the procedure.

However, some measures were successfully adhered to such as the appropriate time for hair removal when necessary; antimicrobial prophylaxis regarding the choice and timing of administration of agent; not using accessories on hands or forearms by surgical teams; the proper use of surgical mask, coat/gown and sterile gloves.

The measures that were not adhered to may indicate negligence or lack of knowledge by professionals on the importance of adherence to these basic recommendations by agencies / reference institutions on the subject. Thus, it is suggested to carry out training and professional skills that underscore the importance of implementing these measures in everyday practice, as well as monitoring their employment in order to improve the quality of care for the safety of the surgical patient.

\section{RESUMO}

Objetivo: Avaliar as práticas pré e intraoperatórias adotadas pelas equipes médicas e de enfermagem visando à prevenção de infecções cirúrgicas. Método: Estudo prospectivo realizado no período de abril e maio de 2013, em um centro cirúrgico de um hospital universitário de Belo Horizonte, Minas Gerais. Resultados: Foram acompanhadas 18 cirurgias e analisadas 214 luvas das quais 23 (10,7\%) tiveram perfuração detectada pós-cirurgia, sendo $52,2 \%$ percebidas pelos usuários. A tricotomia foi feita em $27,7 \%$ dos pacientes na sala de cirurgia usando-se lâminas em $80 \%$ dos casos. A antibioticoprofilaxia foi administrada em 81,8\% dos pacientes até 60 minutos antes da incisão cirúrgica. Verificou-se uma média de nove profissionais presentes durante a cirurgia e a porta da sala de cirurgia se manteve aberta em 94,4\% dos procedimentos. Conclusão: Identificou-se a adesão parcial às medidas recomendadas, reafirmando uma necessidade de maior atenção a estas etapas críticas com o objetivo de prevenir a infecção do sítio cirúrgico.

\section{DESCRITORES}

Infecção da Ferida Operatória; Salas Cirúrgicas; Luvas Cirúrgicas; Controle de Infecções; Enfermagem Perioperatória.

\section{RESUMEN}

Objetivo: Evaluar las prácticas pre e intraoperatorias adoptadas por los equipos médicos y de enfermería con vistas a la prevención de infecciones quirúrgicas. Método: Estudio prospectivo llevado a cabo en el período de abril a mayo de 2013, en un quirófano de un hospital universitario de Belo Horizonte, Minas Gerais. Resultados: Fueron acompañadas 18 cirugías y analizados 214 guantes, de los que $23(10,7 \%)$ tuvieron perforación detectada post cirugía, siendo el 52,2\% percibidas por los usuarios. La tricotomía se hizo en 
el 27,7\% de los pacientes en el quirófano, empleándose láminas en el $80 \%$ de los casos. La antibioticoprofilaxia fue administrada en el 91,8\% de los pacientes hasta 60 minutos previos a la incisión quirúrgica. Se verificó un promedio de nueve profesionales presentes durante la cirugía y la puerta del quirófano se mantuvo abierta en el 94,4\% de los procedimientos. Conclusión: Se identificó la adhesión parcial a las medidas recomendadas, reafirmando la necesidad de mayor atención a esas etapas críticas a fin de prevenir la infección del sitio quirúrgico.

\section{DESCRIPTORES}

Infección de Herida Operatoria; Quirófanos; Cirugía General; Guantes Quirúrgicos; Control de Infecciones; Enfermería Perioperatoria.

\section{REFERENCES}

1. Mangram AJ, Horan TC, Pearson ML, Silver LC, Jarvis WR; The Hospital Infection Control Practices Advisory Committee. Guideline for prevention of surgical site infection. Infect Control Hosp Epidemiol. 1999;20(4):247-78.

2. Brasil. Ministério da Saúde; Agência Nacional de Vigilância Sanitária. Sítio Cirúrgico. Critérios Nacionais de Infecções relacionadas à assistência à saúde. Brasília: MS; 2009.

3. Anderson DJ. Surgical site infections. Infect Dis Clin North Am. 2011;25(1):135-53.

4. Martone WJ, Nichols RL. Recognition, prevention, surveillance, and management of surgical site infections: introduction to the problem and symposium overview. Clin Infect Dis. 2001;33 Suppl 2:S67-8.

5. Tovar JR, Badia JM. Prevention of surgical site infection in abdominal surgery: a critical review of the evidence. Cir Esp. 2014;92(4):223-31.

6. National Institute for Health and Clinical Excellence. Guidance. Surgical Site Infection: prevention and treatment of surgical site infection. London: RCOG; 2008.

7. Alexander JW, Solomkin JS, Edwards MJ. Updated recommendations for control of surgical site infection. Ann Surg. 2011;253(6):1082-93.

8. Durando P, Bassetti M, Orengo G, Crimi P, Battistini A, Bellina D, et al.; Surgical Audit Team of the San Martino University Hospital of Genoa. Adherence to international and national recommendations for the prevention of surgical site infections in Italy: results from an observational prospective study in elective surgery. Am J Infect Control. 2012;40(10):969-72.

9. Centers for Disease Control and Prevention; National Healthcare Safety Network. July 2013 CDC/NHSN Protocol Clarifications. ProcedureAssociated Events SSI [Internet]. [cited 2013 Aug 20]. Available from: http://www.cdc.gov/nhsn/pdfs/pscmanual/9pscssicurrent.pdf

10. European Standard for Medical. EN 455-1:2000. Medical glove for single use. Berlin; 2000.

11. Gould DJ, Drey NS, Creedon S. Routine hand hygiene audit by direct observation: has nemesis arrived? J Hosp Infect. 2011;77(4):290-3.

12. Associação Paulista de Estudos e Controle de Infecção Hospitalar. Prevenção da infecção de sítio cirúrgico. São Paulo: APECIH; 2009.

13. Najjar PA, Smink DS. Prophylatics antibiotics and prevention of surgical site infection. Surg Clin N Am. 2015;95(2):269-83.

14. Spruce L. Back to basics: preventing surgical site infection. AORN J. 2014; 99(5):600-11.

15. Organização Mundial da Saúde. Segundo desafio global para a segurança do paciente: cirurgias seguras salvam vidas. Brasília: OPAS/ MS/ANVISA; 2009.

16. Braswell ML, Spruce L. Implementing AORN recommended practices for surgical attire. AORN J. 2012; 95(1):122-37, 138-40.

17. Harnoss JC, Partecke LI, Heidecke CD, Hübner NO, Kramer A, Assadian O. Concentration of bacteria passing through puncture holes in surgical gloves. Am J Infect Control. 2010;38(2):154-8.

18. Castro-Peraza ME, Garzón-Rodríguez E, Rodríguez-Pérez V, Sosa-Alvarez I, Gutierrez-Hernández J, Asiain-Ugarte C. Incidencia de la perforación de los guantes en cirurgía y efecto protector del doble guante. Enferm Clin. 2010;20(2):73-9.

19. Partecke IL, Goerdt AM, Langner I, Jaeger B, Assadian O, Heidecke CD, et al. Incidence of microperforation for surgical gloves depends on duration of wear. Infect Control Hosp Epidemiol. 2009;30(5):409-14.

20. Oliveira AC, Gama CS. Evaluation of surgical glove integrity during surgery in a Brazilian teaching hospital. Am J Infect Control. 2014;42(10):1093-6.

21. Timler D, Bończak O, Jończyk J, Iltchev P, Sliwczyński A, Marczak M. Risk assessment of accidental exposure of surgeons to blood during orthopedic surgery. Are we safe in surgical gloves? Ann Agric Environ Med. 2014;21(1):212-6.

22. Thomas-Copeland J. Do surgical personnel really need to double-glove? AORN J. 2009;89(2):322-8.

23. Beldame J, Lagrave B, Lievain L, Lefebvre B, Frebourg N, Dujardin F. Surgical glove bacterial contamination and perforation during total hip arthroplasty implantation: when gloves should be changed. Orthop Traumatol Surg Res. 2012; 98(4):432-40.

24. Dawson-Bowling S, Smith J, Butt D, Cottam H, Umasankar S, Armitage A. Should outer surgical gloves be changed intraoperatively before orthopaedic prosthesis implantation? J Hosp Infect. 2011;78(2):152-9.

25. Hübner NO, Goerdt AM, Stanislawski N, Assadian O, Heidecke CD, Kramer A, et al. Bacterial migration through punctured surgical gloves under real surgical conditions. BMC Infect Dis. 2010;10:192.

26. Korniewicz D, El-Masri M. Exploring the benefits of double gloving during surgery. AORN J. 2012;95(3):328-36.

27. Moura MLO, Mendes W. Avaliação de eventos adversos cirúrgicos em hospitais no Rio de Janeiro. Rev Bras Epidemiol. 2012;15(3):523-35.

28. Bohomol E, Tartali JA. Adverse effects in surgical patients: knowledge of the nursing professionals. Acta Paul Enferm. 2013;26(4):376-81. 